University of Nebraska - Lincoln

DigitalCommons@University of Nebraska - Lincoln

Effects of Diet on Population Growth of Psocids Lepinotus reticulatus and Liposcelis entomophila

G. P. Opit

USDA-ARS, george.opit@ars.usda.gov

James E. Throne

USDA-ARS, Manhattan, KS, james.throne@ars.usda.gov

Follow this and additional works at: https://digitalcommons.unl.edu/usdaarsfacpub

Opit, G. P. and Throne, James E., "Effects of Diet on Population Growth of Psocids Lepinotus reticulatus and Liposcelis entomophila" (2008). Publications from USDA-ARS / UNL Faculty. 2016.

https://digitalcommons.unl.edu/usdaarsfacpub/2016

This Article is brought to you for free and open access by the U.S. Department of Agriculture: Agricultural Research Service, Lincoln, Nebraska at DigitalCommons@University of Nebraska - Lincoln. It has been accepted for inclusion in Publications from USDA-ARS / UNL Faculty by an authorized administrator of DigitalCommons@University of Nebraska - Lincoln. 


\title{
Effects of Diet on Population Growth of Psocids Lepinotus reticulatus and Liposcelis entomophila
}

\author{
G. P. OPIT ${ }^{1}$ AND J. E. THRONE \\ USDA-ARS, Grain Marketing and Production Research Center, 1515 College Avenue, Manhattan, KS, 66502-2736
}

J. Econ. Entomol. 101(2): 616-622 (2008)

\begin{abstract}
We investigated the suitability of 11 diets as culture media for the psocids Lepinotus reticulatus Enderlein (Psocoptera: Trogiidae) and Liposcelis entomophila (Enderlein) (Psocoptera: Liposcelididae). The culture media comprised six diets made of plain cereals, namely, wheat (Triticum aestivum L.), corn (Zea mays L.), milo Sorghum bicolor (L.), barley (Hordeum vulgare L.), oats (Avena sativa L.), and rice (Oryza sativa L.), and five artificial diets. We found that, with the exception of corn, L. reticulatus population increase was greater on plain cereal diets than on artificial diets, and the greatest population growth was on oats. There was an inverse relationship between L. reticulatus population growth and diet compactness. L. entomophila populations grew fastest on wheat, barley, and a mixture of cracked wheat, rice krispies, and brewer's yeast (97:2:1, wt:wt). The proportion of females was greater in diets that were less suitable for $L$. entomophila population growth compared with that in the more suitable diets. Diet compactness had a weak effect on L. entomophila population growth. This study also has established the relative level of suitability of damaged wheat, corn, milo, barley, oats, and rice to L. reticulatus and L. entomophila.
\end{abstract}

KEY WORDS Psocoptera, sex ratio, artificial diets, stored products, booklice

Until recently, psocids had been considered only as nuisance secondary pests of minor economic importance (Nayak 2006). However, in the last decade, psocids have become a growing problem in grain storages on farms, collection centers, export terminals, warehouses with bagged commodities, and grain processing facilities worldwide. Heavy psocid infestations can lead to serious germ damage in stored grain (Watt 1965, Kucerova 2002), and they can cause health problems by transferring microorganisms and contaminating food materials with their feces and cast skins ( $\mathrm{Obr}$ 1978, Sidik et al. 1986). The rise in relative importance of psocids can be attributed to their varied response to management tactics that have been developed for beetle pests (Nayak et al. 1998, 2002a, 2002b, 2003; Nayak 2006) and that markets increasingly view psocids as contaminants (Nayak 2006). Most of the psocids infesting stored products and bulk grain belong to two cosmopolitan families: Liposcelididae (Kalinovic and Ivezic 1996) and Trogiidae. Knowledge of the suitability of different cereal grains for psocid pests in these two families is important for their management. However, no studies have been conducted to assess the level of suitability of different cereals for psocids.

Mention of trade names or commercial products in this publication is solely for the purpose of providing specific information and does not imply recommendation or endorsement by the U.S. Department of Agriculture.

${ }^{1}$ Corresponding author, e-mail: george.opit@ars.usda.gov.
To facilitate research, several diets have been used to culture psocids of the genus Liposcelis, and these include mixtures of: 1) whole wheat, kibbled wheat, whole wheat flour, and brewer's yeast (10:10:10:0.1, vol:vol) (Nayak and Collins 2001; we refer to this diet as the Nayak wheat diet);2) enriched white wheat flour and brewer's yeast (20:1,wt:wt) (Mills et al. 1992; Mills flour diet); 3) whole brown rice, ground brown rice, and fine ground skimmed-milk powder (85:10:5, wt:wt) (Rees and Walker 1990; Rees rice diet); 4) whole wheat flour, skim milk, and yeast powder (10: 1:1, wt:wt) (Leong and Ho 1990, Wang et al. 1999, Leong flour diet); 5) wheat flour, wheat germ, yeast, and skimmed milk powder (5:5:5:1, wt:wt) (Mashaya 1999; Mashaya flour diet); and 6) cracked wheat, rice krispies, and brewers yeast (97:2:1, wt:wt), which is the psocid diet that we are currently using for culturing psocids in our laboratory (cracked wheat diet). We are not aware of any published studies on suitable diets for culturing psocids except for those in the genus Liposcelis. We have found no published comparisons of the aforementioned six artificial diets with plain cereals for suitability in culturing psocids of the genus Liposcelis. The only comparison of diets for culturing psocids that we are aware of was a study by Nayak and Collins (2001) who assessed the suitability of five artificial diets for culturing psocids of the genus Liposcelis.

Liposcelis entomophila (Enderlein) (Psocoptera: Liposcelididae) and Lepinotus reticulatus Enderlein 
(Psocoptera: Trogiidae) are two species of psocids that are commonly found associated with bulk grain. In a sampling study, we conducted in 2004 , we found large numbers of these two species infesting wheat stored in steel bins in Manhattan, KS (Throne et al. 2006). Our objectives were to 1 ) assess the level of suitability of different cereal grains for L. entomophila and L. reticulatus and 2) compare published Liposcelis diets and our cracked wheat diet with plain cereals for their suitability for culturing $L$. entomophila and $L$. reticulatus.

\section{Materials and Methods}

Insects. Cultures used in the study were started with insects collected during the summer of 2004 in wheat stored in steel bins at the Grain Marketing and Production Research Center in Manhattan, KS. Voucher specimens of L. reticulatus and L. entomophila used in this study were deposited in the Kansas State University Museum of Entomological and Prairie Arthropod Research under Lot Numbers 181 and 182, respectively. Both psocid species were reared on a mixture of $97 \%$ cracked hard red winter wheat, $2 \%$ rice krispies (Kellog USA Inc., Battle Creek, MI), and 1\% brewer's yeast (MP Biomedicals, Solon, $\mathrm{OH}$ ) (wt:wt; cracked wheat diet) in 0.473-liter glass canning jars covered with mite-proof lids. Cultures were maintained at $30^{\circ} \mathrm{C}, 75 \% \mathrm{RH}$, and 24 -h scotophase.

The mite-proof lid allows air and moisture movement but prevents mites from entering the jar. The mite-proof lid is made by punching a 4-cm-diameter hole in the 6-cm-diameter canning jar lid. The hole is then covered by soldering a 5 -cm-diameter U.S. \#40 mesh (0.42-mm openings) brass screen to the outside of the lid. A 7-cm-diameter filter paper is then placed on either side of the lid, and the lid is placed in the band used to secure the lid to the jar.

Effects of Diet on L. reticulatus Population Growth. Diets. We compared the population growth of L. reticulatus on six plain cereal diets and five artificial diets recommended for culturing psocids of the genus $\mathrm{Li}$ poscelis (Nayak and Collins 2001, Mills et al. 1992, Rees and Walker 1990, Leong and Ho 1990, Wang et al. 1999, our unpublished data). The varieties of plain cereal diets used were Jagger hard red winter wheat(Triticum aestivum L.), Asgrow RX899 corn (Zea mays L.), Cocodrie rice (Oryza sativa L.), F1000 milo (Sorghum bicolor [L.]), Morton F-02 oats (Avena sativa L.), and Excel barley (Hordeum vulgare L.). We first characterized the particle sizes of the ground cereals because we expected the cereals to respond to grinding differently, and particle size can impact stored-product insect population growth (Throne and Culik 1989). Therefore, before commencing the experiment, three 5 -g samples of each of these six cereals were ground separately for $5 \mathrm{~s}$ by using a Waring commercial blender (model 91-262, Waring, New Hartford, CT) adjusted to the low setting, and the resulting grain particles were characterized by pouring a ground sample into a U.S. \#10 sieve (2.00-mm openings) on top of a U.S. \#70 sieve (0.21-mm openings), which was in turn placed on top of a collecting pan; shaking for $5 \mathrm{~s}$; and weighing to the nearest $0.1 \mathrm{~g}$ the portions of the grain components retained on the two sieves and collecting pan.

Insect Culture. One- to 2-wk-old female L. reticulatus were obtained by placing $1 \mathrm{~g}$ of colored psocid diet, 10 particles of cracked wheat, and 30 adult female psocids ( $L$. reticulatus is an obligate parthenogen [Mockford 1993]), so only females are produced) of unknown age from our culture into each of eighty 35-mm-diameter petri dishes (Greiner Bio-One, Kaysville, UT), which had a coat of Fluon (Northern Products, Woonsocket, RI) on the walls to prevent psocids from escaping. Colored diet was made by mixing $100 \mathrm{~g}$ of rice krispies with a solution of $5 \mathrm{ml}$ of red food dye (Global ChemSources Inc., Cedar Grove, $\mathrm{NJ}$ ) in $300 \mathrm{ml}$ of water, drying the mixture in a mechanical convection oven (model HTM 85, Precision Scientific, Inc., Chicago, IL) over a 2-d period, and then grinding the dried mixture in a Wiley Mill by using a \#20 sieve (0.85-mm openings) (Scientific Apparatus, Philadelphia, PA). Colored diet was used because $L$. reticulatus prefers laying eggs between diet particles, and colored diet makes it easier to see eggs and, therefore, to make an assessment of whether sufficient numbers of eggs are being laid for the experiment. The petri dishes were placed on false floors in three Rubbermaid plastic boxes ( 30 by 23 by $9 \mathrm{~cm}$ in height) that contained saturated $\mathrm{NaCl}$ solution below their false floors to maintain $70 \pm 5 \% \mathrm{RH}$ (Greenspan 1977). The boxes had been painted black to exclude light and mimic dark conditions inside steel grain bins. Boxes were placed in an incubator maintained at $30 \pm 1{ }^{\circ} \mathrm{C}$ and $70 \pm 5 \% \mathrm{RH}$. Psocids were removed from each petri dish after $7 \mathrm{~d}$, and the contents of all the petri dishes were poured into a 0.473liter glass canning jar containing $250 \mathrm{~g}$ of cracked wheat diet. The top part ("neck") of the jar had a coat of Fluon and was closed using a mite-proof lid. The jar, in a black plastic box ( 40 by 28 by $23 \mathrm{~cm}$ in height), was placed back in the incubator. After $30 \mathrm{~d}$ from the time psocids (mothers) were removed from petri dishes, adult psocids (offspring) found in the jar were $\approx 1$ 2-wk old (based on the 7-d oviposition period and preliminary work we had done that indicated that development from egg to adult took $\approx 25 \mathrm{~d}$ at $30^{\circ} \mathrm{C}$ ).

Experimental Setup. For the experiment, $5 \mathrm{~g}$ of each of the eleven diets was placed into each of eighteen 35by 60 -mm plastic vials with snap-cap screen lids. The top $2 \mathrm{~cm}$ of each vial wall had a coat of Fluon to prevent psocids from escaping; altogether 198 vials were used. The grain diets were obtained by weighing out eighteen 5-g samples of each of these six cereals, grinding each sample separately for 5 s by using a Waring commercial blender (model 91-262) adjusted to the low setting, and placing the ground product into a vial. The rest of the diets were obtained by measuring out each of the components required to make $5 \mathrm{~g}$ of the diet in the proportions stated, placing these components into a vial, and shaking the vial gently to mix the components.

Three vials containing each type of diet were placed 
into each of six black plastic boxes ( 40 by 28 by $16 \mathrm{~cm}$ in height) with saturated $\mathrm{NaCl}$ solution, i.e., each box contained 33 vials. The placement of vials in each box was such that there were three blocks (groups) of 11 randomly placed vials in each box. One block of vials was placed on each short side of a box, and the remaining block was placed in the middle of the box. The boxes were then placed in an incubator maintained at $30 \pm 1^{\circ} \mathrm{C}$ with a photoperiod of 12:12 (L:D) h. The contents of the vials were left to equilibrate under these conditions for $4 \mathrm{wk}$. Five 1- to 2 -wk-old adult $L$. reticulatus were then placed into each vial. Vials were then returned to their respective boxes and maintained at $30 \pm 1{ }^{\circ} \mathrm{C}, 70 \pm 5 \% \mathrm{RH}$, and a 24 -h scotophase. After $32 \mathrm{~d}$, all motile $L$. reticulatus in each vial were counted by pouring the contents of each vial into a 9-cm petri dish with Fluon-coated walls and examining the contents under a dissecting microscope. The number of nymphs and adults found in each vial were noted. To monitor temperature and relative humidity, two data loggers (HOBO model U12, Onset Computer Corporation, Bourne, MA) were placed in each box; one data logger was used to record temperature data for the duration of the experiment, and the other data logger was checked every 4-6 d to ensure that the temperature and relative humidity in each box were at the desired level.

At the end of the experiment, before counting psocids, the proportion of diet compacted was determined because we noticed that some diets were more compacted than others and we suspected that compactness might impact psocid population growth. Three blocks of vials were used to assess the compactness of diets.

Using two vials of each diet with no psocids present, we also conducted a test to determine whether compacting of diets was a result of insect activity. Vials were kept at $30 \pm 1{ }^{\circ} \mathrm{C}, 70 \pm 5 \% \mathrm{RH}$, and 24 -h scotophase for $1 \mathrm{wk}$ after which the proportion of diet compacted was assessed. We defined compactness as the proportion of diet in a vial that was stuck together in the largest lump of diet after $5 \mathrm{~s}$ of gently shaking the vial in the horizontal position.

All statistical procedures were conducted using Statistical Analysis System software (SAS Institute 2001). The experimental design used for determining the effect of diet on the population growth of $L$. reticulatus was a randomized complete block design (RCBD) with 18 replications (three replications per box). PROC GLM was used for analysis of variance (ANOVA) to determine the effects of diet on the total number of psocids in vials, which were transformed using the square-root transformation to stabilize variances before analysis. Results were reported as untransformed means \pm standard errors. The experimental design used for determining the effect of diet on the percentage weight of cereal components and the proportion of diet compacted was also a RCBD. In both cases there were three replications, PROC GLM was used for ANOVA, and the arcsine transformation was used to stabilize variances before analysis. Results were reported as untransformed means \pm standard errors. We also regressed the proportion of diet compacted against the number of $L$. reticulatus produced
Table 1. Percentage weight (mean $\pm \mathrm{SE} ; n=3$ replications) of grain particles retained in sieves of different sizes

\begin{tabular}{llcc}
\hline \hline Cereal $^{a}$ & $\begin{array}{c}\text { \% wt retained } \\
\text { on \#10 sieve }\end{array}$ & $\begin{array}{c}\text { \% wt retained } \\
\text { on \#70 sieve }\end{array}$ & $\begin{array}{c}\% \text { wt passing } \\
\text { through \#70 sieve }\end{array}$ \\
\hline Barley & $88.7 \pm 0.67 \mathrm{a}$ & $9.3 \pm 0.67 \mathrm{~d}$ & $2.0 \pm 0.00 \mathrm{~b}$ \\
Wheat & $84.7 \pm 3.33 \mathrm{ab}$ & $12.0 \pm 2.00 \mathrm{~d}$ & $3.3 \pm 1.33 \mathrm{ab}$ \\
Oats & $76.7 \pm 2.67 \mathrm{bc}$ & $20.7 \pm 3.33 \mathrm{c}$ & $2.0 \pm 0.00 \mathrm{~b}$ \\
Rice & $74.0 \pm 2.31 \mathrm{c}$ & $23.3 \pm 0.67 \mathrm{bc}$ & $2.0 \pm 0.00 \mathrm{~b}$ \\
Corn & $64.0 \pm 3.06 \mathrm{~d}$ & $30.0 \pm 3.06 \mathrm{~b}$ & $4.7 \pm 0.67 \mathrm{a}$ \\
Milo & $50.0 \pm 2.00 \mathrm{e}$ & $46.0 \pm 2.00 \mathrm{a}$ & $4.7 \pm 0.67 \mathrm{a}$ \\
\hline
\end{tabular}

ANOVA results for components retained on \#10 and \#70 sieves and those that passed through \#70 sieve were $F=25.4, P<0.01 ; F=30.5$, $P<0.01$; and $F=4.91, P=0.02$, respectively; in all cases $\mathrm{df}=5,10$. Means within a column followed by the same letter are not significantly different using least significant difference (LSD) test.

${ }^{a}$ The grains were ground for $5 \mathrm{~s}$ by using a commercial blender before sieving.

using TableCurve 2D (Systat Software, Inc. 1996) to determine whether a relationship existed between these parameters.

Effects of Diet on L. entomophila Population Growth. Methods used were similar to those in the previous experiment except for the following differences: L. entomophila is known from both sexes, but we needed only 1 - to 2 -wk-old females to set up this experiment. To obtain 1- to 2-wk-old female L. entomophila, adult female psocids of unknown age were allowed to lay eggs over a 1 -wk period in 35-mmdiameter petri dishes containing colored diet and cracked wheat. Females are easily distinguishable from males because they are much larger (Leong and Ho 1995) and more boldly marked. Eggs laid by females of unknown age were left to develop to 1- to 2 -wk-old adults over a 30-d period because it takes $L$. entomophila $22 \mathrm{~d}$ to develop from egg to adult at $30^{\circ} \mathrm{C}$ and $75 \%$ RH (Leong and Ho 1995). This experiment had 12 replications, and five female L. entomophila

Table 2. Number (mean $\pm \mathrm{SE} ; n=18$ replications) of $L$. reticulatus on different diets and the proportion (mean $\pm \mathrm{SE} ; \boldsymbol{n}=$ 3 replications) of the total volume of diet compacted at the end of L. reticulatus rearing activities

\begin{tabular}{lcc}
\hline \hline \multicolumn{1}{c}{ Diet } & $\begin{array}{c}\text { No. } \\
\text { L. reticulatus }\end{array}$ & $\begin{array}{c}\text { Proportion of } \\
\text { diet compacted }\end{array}$ \\
\hline Oats & $174.72 \pm 5.93 \mathrm{a}$ & $0.00 \pm 0.00 \mathrm{e}$ \\
Rice & $134.39 \pm 12.47 \mathrm{~b}$ & $0.00 \pm 0.00 \mathrm{e}$ \\
Barley & $119.33 \pm 5.24 \mathrm{~b}$ & $46.7 \pm 8.82 \mathrm{c}$ \\
Milo & $114.94 \pm 5.64 \mathrm{~b}$ & $50.0 \pm 5.77 \mathrm{c}$ \\
Wheat & $114.78 \pm 8.54 \mathrm{~b}$ & $11.7 \pm 4.41 \mathrm{~d}$ \\
Rees rice diet & $70.83 \pm 7.26 \mathrm{c}$ & $0.00 \pm 0.00 \mathrm{e}$ \\
Nayak wheat diet & $47.17 \pm 5.83 \mathrm{~d}$ & $88.3 \pm 1.67 \mathrm{~b}$ \\
Cracked wheat diet & $36.72 \pm 4.17 \mathrm{~d}$ & $56.7 \pm 3.33 \mathrm{c}$ \\
Corn & $17.94 \pm 6.41 \mathrm{e}$ & $93.3 \pm 1.67 \mathrm{ab}$ \\
Mills flour diet & $6.89 \pm 1.20 \mathrm{e}$ & $100.0 \pm 0.00 \mathrm{a}$ \\
Leong flour diet & $6.17 \pm 0.87 \mathrm{e}$ & $100.0 \pm 0.00 \mathrm{a}$ \\
\hline
\end{tabular}

Means within a column followed by the same letter are not significantly different using LSD test.

${ }^{a}$ Five adult female L. reticulatus were placed in each vial at the start of the exp, which lasted $32 \mathrm{~d}$.

${ }^{b}$ Proportion of diet compacted is defined as the proportion of the total volume of media in a vial that was stuck together in the largest lump of diet after $5 \mathrm{~s}$ of gently shaking the vial in the horizontal position. 

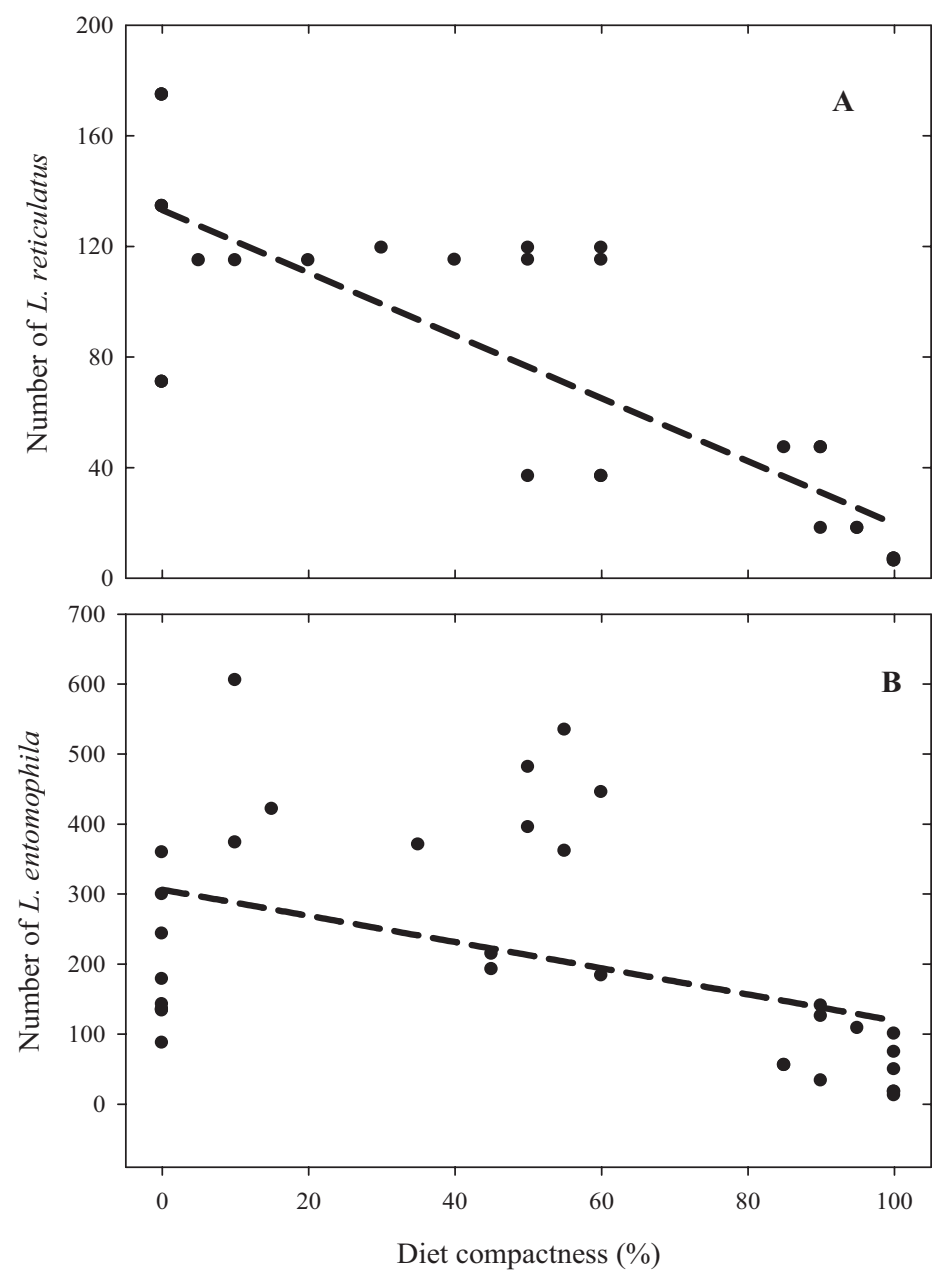

Fig. 1. Relationship between the number of psocids and the proportion of diet compacted. (A) The linear equation $y=$ $133-1.14 \mathrm{x}$ (maximum attainable $R^{2}=0.72 ; R^{2}=0.68 ; F=66.0 ; \mathrm{df}=1,31 ; P<0.01$ ) described the relationship between the number of $L$. reticulatus and the proportion diet compacted. (B) The linear equation y $=306-1.87 \mathrm{x}$ (maximum attainable $\left.R^{2}=0.82 ; R^{2}=0.20 ; F=8.0 ; \mathrm{df}=1,31 ; P<0.01\right)$ described the weak relationship between the number of $L$. entomophila and the proportion of diet compacted.

were placed in each of 132 vials. At the end of the experiment, the numbers of nymphs and adult males and females were counted.

Statistical analyses were conducted as in the previous experiment. In addition, we tested for the effects of diet on sex ratio by using the proportion of females as the response variable, and we determined whether proportion of females varied with treatment (diet) and whether it differed from 0.5 by analyzing data by using PROC GLIMMIX with a binomial option and a logistic link function.

\section{Results}

Effects of Diet on L. reticulatus Population Growth. Characterization of Plain Cereal Diets. Wheat, barley, oats, and rice had a greater percentage of large particles than corn or milo (Table 1).
Number of L. reticulatus. With the exception of corn, higher numbers of $L$. reticulatus developed on plain cereal diets than on the artificial diets (Table 2; $F=88.4 ; \mathrm{df}=10,170 ; P<0.001)$. The greatest population growth was on oats, whereas the lowest population growth was on corn, Mills flour diet, and Leong flour diet.

Compactness of Diets. Plain cereal diets generally were less compact than the artificial diets (Table $2 ; F=$ $193.1 ; \mathrm{df}=10,20 ; P<0.001$ ), except for corn and Rees rice diet. The proportion of diet compacted in diets where psocids were excluded were similar to those of diets where psocids were present $(F=21.44 ; \mathrm{df}=10$, $10 ; P<0.001$ ) (data not shown).

Correlation between Compactness and the Number of L. reticulatus. There was a strong negative linear relationship between the proportion of diet compacted and the number of $L$. reticulatus (Fig. 1A). 
Table 3. Number of adults and proportion of females (mean $\pm \mathrm{SE} ; \boldsymbol{n}=12$ replications) of L. entomophila on different diets and the proportion (mean $\pm \mathrm{SE} ; n=3$ replications) of the total volume of diet compacted at the end of $L$. entomophila rearing activities

\begin{tabular}{lccc}
\hline \hline \multicolumn{1}{c}{ Diet } & $\begin{array}{c}\text { No. } \\
\text { L. entomophila }\end{array}$ & $\begin{array}{c}\text { Proportion of diet } \\
\text { compacted }^{b}\end{array}$ & $\begin{array}{c}\text { Poportion of } \\
\text { females }^{c}\end{array}$ \\
\hline Wheat & $501.5 \pm 43.70 \mathrm{a}$ & $11.7 \pm 1.67 \mathrm{e}$ & $0.55 \pm 0.04 \mathrm{de}$ \\
Barley & $490.1 \pm 25.5 \mathrm{a}$ & $46.7 \pm 6.01 \mathrm{~d}$ & $229.91 \pm 16.80 \mathrm{a}$ \\
Cracked wheat diet & $438.3 \pm 39.97 \mathrm{a}$ & $55 \pm 2.89 \mathrm{c}$ & $230.17 \pm 18.81 \mathrm{a}$ \\
Rees rice diet & $308.8 \pm 13.63 \mathrm{~b}$ & $0.0 \pm 0.00 \mathrm{f}$ & $185.42 \pm 13.27 \mathrm{~b}$ \\
Milo & $275.1 \pm 29.66 \mathrm{~b}$ & $50.0 \pm 5.00 \mathrm{~cd}$ & $184.17 \pm 9.06 \mathrm{~b}$ \\
Rice & $172.0 \pm 12.90 \mathrm{c}$ & $0.0 \pm 0.00 \mathrm{f}$ & $127.50 \pm 8.81 \mathrm{c}$ \\
Oats & $153.8 \pm 12.10 \mathrm{~cd}$ & $0.0 \pm 0.00 \mathrm{f}$ & $126.42 \pm 11.27 \mathrm{c}$ \\
Corn & $146.2 \pm 9.08 \mathrm{~cd}$ & $91.17 \pm 4.46 \mathrm{~d}$ & $0.60 \pm 0.04 \mathrm{bc}$ \\
Leong flour diet & $93.9 \pm 14.42 \mathrm{de}$ & $100.0 \pm 0.00 \mathrm{a}$ & $0.60 \pm 0.05 \mathrm{bcd}$ \\
Nayak wheat diet & $61.2 \pm 8.41 \mathrm{ef}$ & $86.7 \pm 1.67 \mathrm{~b}$ & $0.56 \pm 0.06 \mathrm{cde}$ \\
Mills flour diet & $14.50 \pm 1.14 \mathrm{f}$ & $100.0 \pm 0.00 \mathrm{a}$ & $0.64 \pm 0.06 \mathrm{ab}$ \\
\hline
\end{tabular}

Means within a column followed by the same letter are not significantly different using LSD test.

${ }^{a}$ Five adult female L. entomophila were placed in each vial at the start of the exp, which lasted $32 \mathrm{~d}$

${ }^{b}$ Proportion of diet compacted is defined as the proportion of the total volume of media in a vial that was stuck together in the largest lump of diet after $5 \mathrm{~s}$ of gently shaking the vial in the horizontal position.

${ }^{c}$ In all cases, the $P$ value for the test to determine whether the proportion of females in the adult population was 0.5 was $<0.01$.

Effects of Diet on L. entomophila Population Growth. Number of L. entomophila. The greatest population growth of L. entomophila was on wheat, barley, and cracked wheat diet, whereas the lowest population growth was on Leong flour diet, Nayak wheat diet, and Mills flour diet (Table 3; $F=104.3$;f $=10,109$; $P<0.001)$.

Compactness of Diets. Again, plain cereal diets generally were less compact than the artificial diets (Table $3 ; F=409.79 ; \mathrm{df}=10,20 ; P<0.0001)$, except for corn and Rees rice diet.

Correlation between Compactness and the Number of L. entomophila. There was a weak linear relationship between the proportion of diet compacted and the number of L. entomophila (Fig. 1B).

Sex Ratio. The proportion of females was $>0.5$ in all diets indicating that sex ratio differed from 1:1 in all the diets (Table $3 ; F=8.06$; $\mathrm{df}=10,109 ; P<0.001$ ). The proportion of females in diets that were less suitable for L. entomophila population growth was generally higher compared with the more suitable diets (Table 3).

\section{Discussion}

We observed a negative linear relationship between L. reticulatus population growth and the proportion of diet compacted. Highly compact diets would be expected to limit the movement of insects, and, therefore, the amount of resource available to insects for feeding and reproduction (Nayak and Collins 2001). Based on this, it is not surprising that four of the five diets with the lowest numbers of L. reticulatus had the highest levels of compactness. Another possible explanation for the high number of psocids found in less compact diets is that the larger surface area found in these diets could relieve the potential problem of cannibalism of eggs and nymphs by adults (Broadhead 1954, Leong and Ho 1995, Mills et al. 1992). We also found that compactness of diets where psocids were excluded were similar to those of diets where psocids were present, indicating that compactness of diets is not a result of insect activity but more likely a result of diet particle size.

The numbers of $L$. reticulatus found on plain cereals were greater than those found on other diets, except in corn where compactness was high and the number of psocids found was low. The possible explanation for the comparatively lower compactness in wheat, milo, barley, oats, and rice is that all of them had large intergranular spaces created by the range of particle sizes in these diets. In corn, despite having $64 \%$ of its weight composed of particles at least $2 \mathrm{~mm}$ in size, the compactness was high, and it is possible this could be due to the relatively higher levels of starch (Waldo 1973) and particles $<0.21 \mathrm{~mm}$ in diameter (Table 1) found in corn. Despite that we used ground cereal diets, results of this study provide information on the suitability for L. reticulatus of the six cereals tested when damaged. Based on our data, oats is the most suitable for $L$. reticulatus, followed by rice, barley, milo, and wheat; corn is the least suitable. Bulk grains contain an abundance of damaged kernels (e.g., Mathlein 1971), so these results are expected to be indicative of relative population growth in grain storages.

Despite having compactness of 0 and $57 \%$, respectively, Rees rice diet and cracked wheat diet had significantly lower L. reticulatus numbers compared with plain cereal diets with similar compactness. It is possible that the brewers yeast and powdered milk present in these diets may lead to suppression of $L$. reticulatus population growth. Vials containing diets made of yeast and powdered milk had very strong smells that may indicate fermentation by yeast and bacteria, respectively. It is possible that fermentation products in these diets have a negative effect on $L$. reticulatus; hence, the low number of psocids found in these diets.

After $32 \mathrm{~d}$, oats had the highest number of L. reticulatus - an average number of 175 psocids-which represents a 35-fold increase from an initial population of five adult females. The high rate of population growth on this diet could be due to oats having a compactness level of $0 \%$, and possibly because it has 
Table 4. Amounts of protein, fat, and niacin in wheat, corn, milo, barley, oats, and rice

\begin{tabular}{lcrrrr}
\hline \multicolumn{1}{c}{ Component $^{a}$} & Wheat (hard) & Corn & Barley & Oats & Milo \\
\hline Moisture, \% & 10.0 & 15.0 & 10.6 & 9.8 & 11.4 \\
Protein $(\mathrm{N} \times 6.25), \%$ & 14.3 & 10.2 & 13.0 & 12.0 \\
Fat, \% & 1.9 & 4.3 & 2.1 & 5.1 & 12.5 \\
Niacin, $\mathrm{mg} / \mathrm{kg}$ & 63.6 & 26.6 & 64.5 & 1.3 & 4.4 \\
\hline
\end{tabular}

Data are from Joint United States-Canadian Tables of Feed Composition (1964)

${ }^{a}$ Values reported on moisture-free basis.

high levels of both protein and fat (Table 4, Joint United States-Canadian Tables of Feed Composition 1964). Protein is required for growth, whereas fat is a concentrated source of energy. To place values given in Table 4 within proper context, these values are means and vary with variety.

We found that wheat, barley, and cracked wheat diet had the highest numbers of $L$. entomophila, resulting in 100-, 98-, and 88-fold increases in population, respectively, from the initial L. entomophila populations of five adult females. Unlike $L$. reticulatus, $L$. entomophila reproduction does not seem to be greatly affected by the proportion of diet compacted. Wheat, barley, and cracked wheat diet had low to moderate compactness, yet had higher populations of psocids compared with diets with $0 \%$ compactness (oats, rice, and Rees rice diet). The reason for this may be that $L$. entomophila are more dorsoventrally flattened compared with $L$. reticulatus; hence, they are able to use the compact diets more effectively. In fact, during psocid counts, we often found large numbers of $L$. entomophila in the middle of large lumps of diet, unlike L. reticulatus.

Although we do not have information on the chemical composition of all the 11 diets tested, by using Table 4 and the cracked wheat diet being made up of mostly wheat, it seems that wheat, barley, and cracked wheat diet, with the highest numbers of $L$. entomophila, may have high levels of niacin and protein. Niacin, also known as nicotinic acid or vitamin B3, is important for the proper functioning of many physiological processes (Chang and Li 2004). Diets lacking niacin have been shown to induce physiological malfunctions such as shortened oviposition period (Ozalp and Emre 1992), reduced egg hatch (Tsiropoulos and Hagen 1987), and lowered reproductive rate (Levinson et al. 1992). In Tetranychus urticae Koch, niacin has been shown to stimulate feeding (Dabrowski 1974). Therefore, it is possible that the high numbers of $L$. entomophila found in wheat, barley, and cracked wheat diet could be due to the high levels of niacin and protein.

We also found that diet affected the sex ratio of $L$. entomophila. The proportion of females in diets that were less suitable for L. entomophila was higher compared with that in more suitable diets. Several studies have shown that diet influences sex ratio in many organisms (Bradbury and Blakey 1998; Rosenfeld and Roberts 2004, and references therein; Coskun et al. 2005). Our data, which show diets producing low numbers of L. entomophila have a higher proportion of females, are similar to the findings of Nager et al. (1999) who showed that as female condition declined, and thereby the capacity to produce high-quality eggs declined, the more progressively skewed the ratio of eggs was toward females, i.e., females produced more females because it is the sex with higher prospects of population survival.

We have shown that the proportion of diet compacted is negatively correlated with $L$. reticulatus population growth, that inclusion of yeast and/or powdered milk in L. reticulatus diets may limit population growth, and that $L$. reticulatus populations increase more rapidly on ground cereal diets than on artificial diets. Therefore, we recommend that cultures of $L$. reticulatus for research be maintained on oats, barley, milo, rice, or wheat. We found that L. entomophila populations grew rapidly on wheat, barley, and cracked wheat diet; therefore, we recommend that $L$. entomophila cultures for research be maintained on these diets. We also found that less suitable diets skew L. entomophila sex ratio toward females. We have established the relative level of suitability of broken wheat, corn, milo, barley, oats, and rice to L. reticulatus and L. entomophila. Knowledge of relative suitability of these cereals to L. reticulatus or L. entomophila can aid in improving pest management, e.g., the frequency of monitoring for these pests in storages may be adjusted based on relative rates of population growth.

\section{Acknowledgments}

We thank Ann Redmon, Aakshi Prakash, and Jordan Duff for technical support; we also thank Christos Athanassiou, Edward Mockford, and Steve Pearlman for reviewing an earlier version of this manuscript. In addition, we extend our appreciation to Edward Mockford who helped confirm the identity of L. reticulatus and L. entomophila.

\section{References Cited}

Bradbury, R. B., and J. K. Blakey. 1998. Diet, maternal condition, and offspring sex ratio in the zebra finch, Poephila guttata. Proc. R. Soc. Lond. B 265: 895-899.

Broadhead, E. 1954. The infestation of warehouses and ships' holds by psocids in Britain. Entomol. Mo. Mag. 90: 103-105.

Chang, C. L., and Q. X. Li. 2004. Dosage effects between dietary niacin and other $\mathrm{B}$ vitamins on larval development of Ceratitis capitata (Diptera: Tephritidae). Ann. Entomol. Soc. Am. 97: 536-540.

Coskun, M., P. Ozalp, and I. Emre. 2005. Effects of vitamin E concentrations on sex ratio of Pimpla turionellae (Hy- 
menoptera: Ichneumonidae) adults. Ann. Entomol. Soc. Am. 98: 336-339.

Dabrowski, Z. T. 1974. Studies on the relationships of Tetranychus urticae Koch and host plants. V. Gustatory effect of water-soluble vitamins. Polskie-Pismo-Entomol. 44: $359-372$.

Greenspan, L. 1977. Humidity fixed points of binary saturated aqueous solutions. J. Res. Natl. Bur. Stand. A 81: $89-96$.

Joint United States-Canadian Tables of Feed Composition. 1964. National Academy of Sciences-National Research Council. Publication 1232, Washington, DC.

Kalinovic, I., and M. Ivezic. 1996. List of Psocoptera (Insecta) in Croatia. Entomol. Croat. 2: 11-16.

Kucerova, Z. 2002. Weight losses of wheat grains caused by psocid infestation (Liposcelis bostrychophila: Liposcelididae: Psocoptera). Plant Prot. Sci. 38: 103-107.

Leong, E.D.C., and S. H. Ho. 1990. Techniques in culturing and handling of Liposcelis entomophilus (Enderlein) (Psocoptera: Liposcelidae). J. Stored Prod. Res. 26: 67-70.

Leong, E.C.W., and S. H. Ho. 1995. Life cycle of Liposcelis entomophila (Psocoptera: Liposcelididae) and a culturing regime for liposcelids. Bull. Entomol. Res. 85: 501-506.

Levinson, H. Z., A. R. Levinson, and M. Ofenberger. 1992. Effect of dietary antagonists and corresponding nutrients on growth and reproduction of the flourmite (Acarus siro L. ). Experientia 48: 721-729.

Mashaya, N. 1999. Population dynamics of Liposcelis entomophila (Enderlein) (Psocoptera: Liposcelidae) in farm tobacco processing buildings. J. Stored Prod. Res. 35: $355-368$.

Mathlein, R. 1971. Rearing experiments with Oryzaephilus surinamensis L. and Cryptolestes ferrugineus Steph. on grain. Medd. Statens Växtskyddsanstalt. 15: 187-203.

Mills, J. T., R. N. Sinha, and C. J. Demianyk. 1992. Feeding and multiplication of a psocid, Liposcelis bostrychophilus Badonnel (Psocoptera: Liposcelidae) on wheat, grain screenings, and fungi. J. Econ. Entomol. 85: 1453-1462.

Mockford, E. L. 1993. North American Psocoptera. The Sandhill Crane Press, Inc., Gainesville, FL.

Nager, G. R., P. Monaghan, R. Griffiths, D. C. Houston, and R. Dawson. 1999. Experimental demonstration that offspring sex ratio varies with maternal condition. Ecology 96: $570-573$.

Nayak, M. K. 2006. Psocid and mite pests of stored commodities: small but formidable enemies, pp. 1061-1073. In I. Lorini, B. Bacaltchuk, H. Beckel, D. Deckers, E. Sundfeld, J. P. dos Santos, J. D. Biagi, J. C. Celaro, L. R. D'A. Faroni, L de O. F. Bortolini, et al. [eds.], Proceedings of the 9th International Working Conference on Stored Product Protection, 15-18 October 2006, São Paulo, Brazil. Brazilian Post-harvest Association-ABRAPOS, Passo Fundo, RS, Brazil.

Nayak, M. K., and P. J. Collins. 2001. An improved method for mass rearing three liposcelid psocids (Psocoptera: Liposcelidae) infesting stored commodities. J. Stored Prod. Res. 37: 323-328.

Nayak, M. K., P. J. Collins, and S. R. Reid. 1998. Efficacy of grain protectants and phosphine against Liposcelis bostrychophila, L. entomophila, and L. paeta (Psocoptera: Liposcelidae). J. Econ. Entomol. 91: 1208-1212.

Nayak, M. K., P. J. Collins, and H. Pavic. 2002a. Long-term effectiveness of grain protectants and structural treatments against Liposcelis decolor (Pearman) (Psocoptera:
Liposcelididae), a pest of stored products. Pest Manag. Sci 58: 1223-1228.

Nayak, M. K., P. J. Collins, and H. Pavic. 2002b. Resistance to phosphine in psocids: challenges ahead!, pp. 113-118. In E. J. Wright, H. J. Banks, and E. Highley [eds.], Proceedings of the 2nd Australian Postharvest Technical Conference, 1-4 August 2000, Adelaide, Australia. Stored Grain Research Laboratory, Canberra, Australia.

Nayak, M. K., P. J. Collins, H. Pavic, and R. A. Kopittke. 2003. Inhibition of egg development by phosphine in the cosmopolitan pest of stored products Liposcelis bostrychophila (Psocoptera: Liposcelididae). Pest Manag. Sci 59: 1191-1196.

Obr, S. 1978. Psocoptera of food-processing plants and storages, dwellings and collections of natural objects in Czechoslovakia. Acta Entomol. Bohemoslov 75: 226-242.

Ozalp, P., and I. Emre. 1992. Effect of water-soluble vitamins on egg production and hatchability of adult Pimpla turionellae L. Turk. J. Zool. 16: 78-83.

Rees, D. P., and A. J. Walker. 1990. The effect of temperature and relative humidity on population growth of three Liposcelis species (Psocoptera: Liposcelidae) infesting stored products in tropical countries. Bull. Entomol. Res. 80: 353-358.

Rosenfeld, C. S., and R. M. Roberts. 2004. Maternal diet and other factors affecting offspring sex ratio: a review. Biol. Reprod. 71: 1063-1070.

SAS Institute. 2001. The SAS system for Windows, version 8. SAS Institute, Cary, NC.

Sidik, M., H. Halid, and R. I. Pranata. 1986. Pest problems and the use of pesticides in grain storage in Indonesia, pp. 37-43. In B. R. Champ and E. Highley [eds.], Pesticides and humid tropical grain storage systems. Proceedings, International Seminar, 27-30 May 1985, Manila, Philippines. No. 14. ACIAR Proceedings, Canberra, Australia.

Systat Software, Inc. 1996. TableCurve 2D, version 4.0. Systat Software Inc., San Jose, CA.

Throne, J. E., and M. P. Culik. 1989. Progeny production and duration of development of rusty grain beetles, Cryptolestes ferrugineus (Stephens) (Coleoptera: Cucujidae), on cracked and whole corn. J. Entomol. Sci. 24: 150-155.

Throne, J. E., G. P. Opit, and P. W. Flinn. 2006. Seasonal distribution of psocids in stored wheat, pp. 1095-1103. In I. Lorini, B. Bacaltchuk, H. Beckel, D. Deckers, E. Sundfeld, J. P. dos Santos, J. D. Biagi, J. C. Celaro, L. R. D’A. Faroni, L de O. F. Bortolini, et al. [eds.], Proceedings of the 9th International Working Conference on Stored Product Protection, 15-18 October 2006, São Paulo, Brazil. Brazilian Post-harvest Association-ABRAPOS, Passa Fundo, RS, Brazil.

Tsiropoulos, G. J., and K. S. Hagen. 1987. Effects of nutritional deficiencies produced by antimetabolites on the reproduction of Rhagoletis completa Cresson (Diptera: Tephritidae). J. Appl. Entomol. 103: 351-354.

Waldo, D. R. 1973. Extent and partition of cereal grain starch digestion in ruminants. J. Anim. Sci. 37: 1062-1074

Wang, J. J., J. H. Tsai, Z. M. Zhao, and L. S. Li. 1999. Development and reproduction of the psocid Liposcelis bostrychophila (Psocoptera: Liposcelididae) as a function of temperature. Ann. Entomol. Soc. Am. 93: 261-270.

Watt, M. J. 1965. Notes on pests of stored grain. Liposcelis bostrychophilus and Sitophilus spp., pp. 693-696. Agriculture Gazette, November 1965.

Received 22 May 2007; accepted 27 September 2007. 